\title{
PEDAGOGIAS ALTERNATIVAS E FORMAÇÃO PROFISSIONAL DE ENGENHEIROS: EXPERIÊNCIAS DE APRENDIZAGEM NO CEFET- MG $^{1}$
}

\author{
ALTERNATIVE PEDAGOGIES AND PROFESSIONAL TRAINING IN \\ ENGINEERING EDUCATION AT CEFET-MG
}

J. C. D. PEREIRA ${ }^{1, *}$, A. P. N. TOMASI ${ }^{1}$

${ }_{1}$ Centro Federal de Educação Tecnológica de Minas Gerais - CEFET-MG, Programa de PósGraduação em Educação Tecnológica, Belo Horizonte, Brasil

\section{ARTICLE INFO}

Article history:

Received 2018-07-25

Accepted 2018-12-20

Available online 2018-12-21

*Autor correspondente:

E-mail: julianacdpereira@yahoo.com
Palavras-chave: Saberes. Pedagogias alternativas. Formação profissional. Engenharia. Educação.

Keywords: Knowledge. Alternative pedagogies. Professional training. Engineering. Education.

RESUMO. O campo das ciências da educação tem enfatizado ao longo do tempo inúmeros trabalhos que colocam em relevo uma escola e práticas educativas alternativas à escola tradicional, apontando nessas práticas benefícios para a aprendizagem e a formação do aluno. Esse artigo procura identificar essas práticas, ainda que coexistentes com as práticas tradicionais e detectar as contribuições que os percursos formativos experienciais acrescentam à formação profissional dos alunos. Foram utilizados como campo teórico estudos relativos à formação experiencial, à formação profissional e às pedagogias alternativas, assim como observações e entrevistas. Apresenta-se, aqui, os resultados de uma sondagem inicial

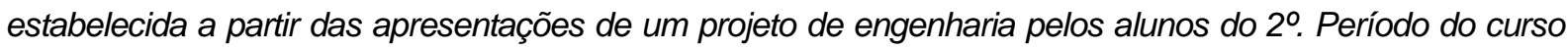
de Engenharia Elétrica do CEFET-MG na disciplina Metodologia de Projetos, e o trabalho que desempenham alunos de diferentes períodos que compõem a Equipe Fórmula Cefast da mesma instituição. A sondagem inicial aponta que os alunos dos cursos de engenharia estudados são capazes de construir conhecimentos a partir de outras vias que não tenham como referência única a sala de aula, e indícios de que os alunos são capazes de construir percursos formativos alternativos àqueles propostos pela escola. Aponta, ainda, a necessidade de a escola repensar suas práticas formadoras.

ABSTRACT. The field of educational sciences has emphasized many researches that highlight a school and the alternative educational practices for the traditional school, pointing in these practices the benefits for the learning and the student's formation. This study tries to identify these practices, although they coexist with the traditional practices, and to detect the contributions that the experiential formative pathway adds to the professional formation of the students. Studies related to experiential formation, professional training and alternative pedagogies, as well as observations and interviews were used as theoretical field. We present here the results of an initial survey established from the presentations of the engineering projects made by the 2nd. semester's students of the Electrical Engineering course of CEFET-MG in the Project Methodology

\footnotetext{
${ }^{1}$ Trabalho apresentado no VII Simpósio Internacional Trabalho, Relações de Trabalho, Educação e Identidade. As modificações são resultado das contribuições feitas a partir da apresentação do trabalho.
} 
discipline, and the work performed by students from different periods that compose the Formula Cefast Team of the same institution. Initial survey indicates that students of engineering courses are able to build knowledge in other ways that do not have the classroom as a single reference, and evidence that students are able to construct alternative pathway to those proposed by the school. It also highlights the need of the school to rethink its formative practices.

\section{Introdução}

Os estudiosos da técnica a apontam como indissociável da emergência do próprio ser humano. Para Ortega y Gasset (1963) a técnica é definida como o conjunto dos atos técnicos empreendidos pelo ser humano na modificação do mundo, na reforma que este impõe à natureza, modificando-a no intuito de satisfazer necessidades e vontades. A técnica é constituinte da natureza humana2. O filósofo define três estágios da técnica, sendo o primeiro a técnica do acaso, o segundo a técnica do artesão e o terceiro a técnica do técnico. O terceiro estágio é o que nos interessa neste trabalho, pelo fato de que é este o estágio o qual pode ser compreendido como tecnologia e é neste estágio que atuam os engenheiros.

A tecnologia na contemporaneidade é um modo de vida, é constituída pelos seres humanos e constituidora deles, dos seus hábitos, dos seus costumes, das suas formas de organizar o pensamento e os engenheiros, além de estarem inseridos neste modo de vida, como quaisquer outros atores, são figuras importantes no mundo da produção e no projeto de soluções e artefatos tecnológicos para os problemas da contemporaneidade. Além disso, é importante ressaltar também que o desenvolvimento e a aplicação da ciência e da tecnologia possuem implicações sociais, políticas e econômicas. A formação profissional de engenheiros é de interesse porque tais profissionais atuam no campo da tecnologia de forma mais ampla que o restante da sociedade.

Nos primórdios, a formação dos engenheiros se dava por uma via que não é a escola e sim a experiência. As escolas de educação técnica e de formação de engenheiros, que deram origem aos modelos de formação profissional que conhecemos hoje, só começaram a emergir na Europa do século XVIII, mais especificamente na França. Um marco importante na tradição da formação profissional foi a fundação da École Polytechnique em 1794. A partir dela emerge um novo modelo de formação de engenheiros civis e militares que combinava alto nível de educação científica com formação técnica baseada num estudo rigoroso dos princípios dos trabalhos práticos.

\footnotetext{
${ }^{2}$ Esta separação entre ser humano e natureza tem sido cada vez mais questionada nas perspectivas pós-estruturalistas, contudo, optou-se por mantê-la a fim de evidenciar que desde os primórdios os seres humanos desenvolveram técnicas.
} 
A Ecole Polytechnique foi a primeira escola a dar instrução teórica e prática e combinar educação e pesquisa, foi a primeira instituição a introduzir o laboratório para o ensino superior e o primeiro estabelecimento de educação superior que era também um centro de pesquisa. (SALOMON, $1984-$ p. 143)3

No Brasil, ainda que tenha havido algumas iniciativas relacionadas à formação profissional por parte dos jesuítas no século XVII ou iniciativas militares nos séculos XVII e $\mathrm{XVIII}$, as escolas de formação profissional nascem com as transformações ocorridas no século XIX, marcadas pelos ideais de progresso do início do processo de industrialização que atinge o Rio de Janeiro4 (Gama, 1986), em 1842, a partir da Escola Militar, é instalado o primeiro curso de engenharia civil no Brasil.

O processo de formação de engenheiros no Brasil, como afirma Amorim (2016), historicamente esteve ligado ao setor produtivo, principalmente ao setor industrial, associado aos interesses das classes dominantes.

Nesse sentido, as faculdades de engenharia tiveram como alvo a preparação de profissionais devidamente instrumentalizados para os aspectos técnicos de sua atividade, que deveria desenrolar-se no âmbito do mundo empresarial em detrimento dos demais. Essa imbricação entre o ensino de engenharia e o chamado setor produtivo, estreitada a partir da intensa industrialização do século XIX, levou os engenheiros a introjetarem permanentemente os valores capitalistas. (AMORIN, 2016, p.24)

Dessa forma, podemos dizer que os cursos de engenharia no Brasil, desde seus primórdios, estão inseridos na perspectiva estrita de formar para adaptação aos postos de trabalho. Conforme Cavalcante, Albuquerque e Jesus (2008, p53), "o modelo produtivista implementado nas empresas é transferido para as escolas, com um excesso de pragmatismo, expresso no discurso 'formar para o mercado' (...) quase a totalidade das escolas (privadas e públicas) incorpora a lógica do cidadão-consumidor, aluno-cliente, algumas com mais recursos tecnológicos, outras apenas no aspecto conceitual". Tal discurso carrega consigo aspectos ideológicos de uma sociedade construída para a individualidade em detrimento da coletividade, composta por sujeitos que aprenderam a direcionar suas vidas a partir de referências competitivas, que estão no cerne da lógica capitalista, e que, estes mesmos sujeitos tendem a enxergar como naturais, presentes na contemporaneidade.

A interface entre a educação e o mundo do trabalho se encontra na formação profissional, que no caso do Brasil, não tem rompido com a concepção de formação

\footnotetext{
${ }^{3}$ Tradução nossa.

${ }^{4}$ Como aponta Gama (1986) "A população urbana aumenta significativamente e o escravismo está em decadência, sofrendo fortes pressões que prenunciam seu fim. As manufaturas e o trabalho livre exigem educação técnica."
} 
adestradora para a manutenção das relações de poder, de classe e de produção vigentes. Neste sentido, é importante a seguinte reflexão: seria o papel da escola apenas a formação do sujeito para a adaptação aos imperativos do mercado?

É importante ressaltar que, apesar dos discursos que emergem na atualidade apontarem o desejo de uma escola despolitizada, não é possível separar a educação e a política, a pedagogia e a política, ou uma prática pedagógica alternativa e política. Como afirma Tomasi (2017, p. 85) os "entendimentos diferentes de educação e da escola nos conduzem a interesses diversos de indivíduos, de grupos e/ou classes sociais". O próprio ato de educar que abarca a escolha dos conteúdos, a adoção destas ou daquelas práticas pedagógicas, as relações escola-aluno, professor aluno e os valores presentes nestas relações já são por si atos essencialmente políticos.

\section{Educação em engenharia, os corpos (e mentes) dóceis e a competência}

O modelo de ensino de engenharia, largamente utilizado no Brasil, segue pedagogias tradicionais e, como afirma Loder (2008), é centrado na figura do professor, visto como dententor do conhecimento e agente principal do processo de aprendizagem dos alunos. São pedagogias que investem na docilidade dos alunos em detrimento da autonomia deles. Outros dois fatores relevantes na análise das ações pedagógicas vigentes no contexto da engenharia residem no fato de que muitos professores são engenheirosprofessores, e grande parte dos engenheiros-professores não atuou como engenheiro fora da universidade. Estes dois fatores podem evidenciar pelo menos duas questões nas ações pedagógicas no contexto da engenharia, o fato de os engenheiros-professores não possuírem formação na área da educação pode os levar a ter uma compreensão superficial da educação, a não enxergar seu caráter constituído e constituinte de uma sociedade desigual e mesmo o seu papel de reprodutora dos valores das classes dominantes e das desigualdades sociais (BOURDIEU, 1992).

O fato de muitos engenheiros-professores não terem tido atuação profissional fora das universidades pode denotar um conhecimento muito restrito acerca dos contextos de atuação dos engenheiros no mundo do trabalho, em constante mudança. Esta questão pode ser encarada como uma consequência do triunfo da escola sobre outras modalidades de formação5, que confina a aprendizagem no tempo e no espaço, ou seja, o local de formação é diferente e distante do local de trabalho. Se dentro da perspectiva do ensino de engenharia, o professor é a figura central na educação que, entre outras finalidades, deve

\footnotetext{
${ }^{5}$ Ver: CAVACO, C., “Aprender fora da escola: percursos de formação experiencial”. Lisboa: Editora Educa, 2002.
} 
também preparar os estudantes para o mundo do trabalho, como o professor deve atuar se, muitas vezes, ele mesmo desconhece a realidade complexa que se desenha no mundo do trabalho fora da universidade? Além do mais, como apontam Silveira, Carmo e Silva (2008, p. 90), "pesquisas demonstram que os estudantes dos cursos de engenharia acompanham mais de perto as opiniões dos que labutam no mercado de trabalho do que os fazem as lentes universitárias". Este questionamento denota a fronteira, ainda bastante intransponível entre a escola e o trabalho.

Para Loder (2008), existe dentre os engenheiros-professores a idéia de que saberfazer é saber-ensinar e as trajetórias formativas pessoais dos professores contribuem para a perpetuação das pedagogias tradicionais.

Uma das causas que se atribui a continuidade do uso dessa pedagogia tradicional, apesar das provas evidentes do esgotamento da mesma é o fato de que os professores que atuam nestes cursos serem, em grande maioria, profissionais formados sobre a pedagogia tradicional, de caráter diretivo, e, por isso mesmo, tem a tendência "natural" de usar e acreditar na eficácia da mesma para garantir ao aluno o aprendizado desejado. (LODER, 2008, p. 22)

Dentro da concepção das pedagogias tradicionais a "transmissão" do conhecimento do professor (e a aprendizagem do aluno) acontece na sala de aula, o "bom aluno" deve estar na sala de aula, em silêncio, no seu lugar, no horário, são métodos que valorizam a docilidade-utilidade dos jovens e desconsideram suas vivências, suas experiências, suas trajetórias e desejos. O foco está nos conteúdos técnicos que são divididos em segmentos e a "transmissão" ordenada destes segmentos acontece sempre na direção do professor para o aluno. Dentro desta perspectiva de docilidade-utilidade, "o aluno é um vazio a ser preenchido" (FREIRE, 2009).

Em contrapartida, as tecnologias e o mundo do trabalho colocam desafios cada vez mais complexos à educação e a vida em sociedade. Com a desestabilização dos sistemas de produção ocorrida na década de 1970 que ocasionou mudanças no padrão de produção industrial e também com a incorporação de novas tecnologias pela indústria, a formação tradicional seguindo o modelo da qualificação, centrada em referências tayloristas-fordistas, se mostra insuficiente para atender as novas demandas colocadas pelo mundo do trabalho, e, no caso das engenharias, esta alegação é evidenciada pelo alargamento dos postos de trabalho dos engenheiros.

As pesquisas indicam que as mudanças na atuação dos engenheiros na sociedade atual apontam para a preponderância de habilidades gerais como saber trabalhar em equipe, ter capacidade de realizar múltiplas tarefas, habilidades em gerenciamento, raciocínio analítico, sobre os saberes técnicos específicos muito embora estes sejam 
também indispensáveis na formação dos profissionais da engenharia6. Tal fenômeno remete a reflexões acerca de modelos focados no indivíduo e suas subjetividades, na sua criatividade, iniciativa, capacidade de mobilização de saberes, flexibilidade. Em contrapartida a esta complexização do mundo do trabalho dos engenheiros, algumas escolas de engenharia parecem compreender o engenheiro apenas na sua função restrita, privilegiando a formação quase puramente teórica e científica nos currículos em detrimento das demais demandas colocadas pelo mundo do trabalho e pelos próprios alunos dos cursos.

Do ponto de vista legislativo, a Resolução do Conselho Nacional de Educação CNE/CES 11, de 11 de março de 2002 institui que os engenheiros possuam formação generalista, humanista, crítica e reflexiva, que sejam capazes de absorver e desenvolver novas tecnologias, que sejam estimulados a atuar de forma crítica e criativa na identificação e resolução de problemas, considerando seus aspectos políticos, econômicos, sociais, ambientais (BRASIL, 2002). Contudo, como afirma Ribeiro (2005) mudanças propostas pelas legislações "parecem ter promovido poucas mudanças significativas nos currículos e na forma como os conteúdos são trabalhados" (RIBEIRO, 2005, p. 10). Para o autor, são diversas as razões para a persistência dos modelos convencionais na educação em engenharia, fatores institucionais, culturais e até mesmo individuais parecem contribuir para que haja resistência a superação dos destes modelos.

Dentre os fatores institucionais Ribeiro (2005) evidencia que as universidades não são instituições ágeis pela forma como são geridas, por meio de resoluções, conselhos, etc. Outros fatores citados pelo autor residem no fato de que as universidades são instituições longevas e conservadoras e, como todos os sistemas humanos, tendem a manter a ordem. Estas características fazem com que as instituições escolares e as universidades "mantenham as formas tradicionais de fazer as coisas, mesmo diante de intensas pressões por mudanças" (DEEBREN, 1973, p. 455 apud RIBEIRO, 2005, p. 11).

Ainda sobre as questões relacionadas à instituição, o autor evidencia que as instituições públicas de ensino superior não têm motivação econômica e não precisam fazer face a concorrências [...], elas tem menos necessidade de se preocupar em melhorar os serviços que proporcionam (HUBERMAN, 1973, p. 44 apud RIBEIRO, 2005, p. 12).

Outro fator apontado por Ribeiro (2005) que precisa ser levado em consideração quanto a perpetuação dos modelos tradicionais de educação na engenharia está

\footnotetext{
${ }^{6}$ Sobre este "alargamento" dos postos de trabalho dos engenheiros ver: SILVEIRA, M. A.; CARMO L. C. S.; PARISE, J. A. R.;CAMPOS, R. C., Pesquisa em Educação em Engenharia. Ver também SILVEIRA, M. A.; CARMO, L. C. S.; SILVA, E. M., "Considerações sobre o mercado de trabalho em engenharia" in Educação, mercado e desenvolvimento: mais e melhores engenheiros. São Paulo: Abenge, 2008.
} 
relacionado a forte influência positivista. Nesta perspectiva o conhecimento é tido como "acabado" e desvinculado do contexto histórico, são modelos que valorizam a memorização dos conceitos, que favorecem o pensamento convergente e a resposta única. Os currículos que predominam no contexto da engenharia são elaborados tendo como referencia uma aprendizagem cumulativa e linear. Silva (2017) faz referência à especialização das disciplinas na engenharia que ocorre na mesma lógica da divisão e especialização do trabalho no modo de produção capitalista.

(...) sendo estas (as disciplinas) conduzidas de forma fragmentada e compartimentalizada em ênfases e disciplinas isoladas que em sua maioria não apresentam interface entre elas, nem com as práticas sociais, nem com a realidade dos estudantes, o que põe em risco a efetividade do aprendizado do engenheiro. (SILVA, 2017, p. 75)

Nos aspectos individuais estão os professores, figuras centrais na pedagogia diretiva amplamente difundida no contexto da formação profissional dos engenheiros. Tanto Ribeiro (2005) quando Loder (2008) apontam como característica principal dos professores de engenharia a carência de formação pedagógica. A concepção vigente é a de que quem sabe, "automaticamente" sabe ensinar. A perspectiva de transmissão dos conhecimentos é predominante e, conforme os autores. é até esperada pelos alunos.

Os procedimentos de avaliação majoritariamente difundidos são quase sempre somativos e raramente contribuem para a formação dos alunos ou para o aprimoramento dos docentes e dos cursos como aponta Ribeiro (2005). Os critérios são determinados pela instituição e o desempenho insatisfatório nas provas é creditado aos alunos ao invés de buscar-se suas causas.

Por estes e outros vários fatores que podem ser levantados a educação em engenharia não consegue superar os modelos tradicionais que favorecem a separação e compartimentação dos saberes. Em contrapartida, o exercício da engenharia no contexto profissional exigirá a integração e mobilização de vários saberes, fora de seus compartimentos. São várias as pesquisas que apontam para a necessidade da superação destes modelos porque tanto a sociedade quanto ao mundo do trabalho dão sinais de que é necessário formar um novo perfil de engenheiro.

O fato é que a engenharia e os cursos de engenharia envolvem, em suas várias especialidades, vários saberes e espera-se que o engenheiro domine e saiba integrar saberes disciplinares (...) além de ser apto a aplicá-los em seus múltiplos campos de aplicação (...). (SILVA, 2017, p. 75)

O que está em questão nas novas configurações do mundo do trabalho de que fazem parte os engenheiros, diz respeito à qualificação, mas diz respeito também à competência. "A noção de competência vem do latim competentia, derivada de competere, "chegar ao mesmo ponto”, oriunda de petere, 'dirigir-se para'. Refere-se a 'o que convém'; 
no francês antigo significava 'apropriado' " (DADOY, 2004, p.108). Para Dugué (2004), a noção de competência remete a uma mistura de saber e de comportamento frente às situações de trabalho, definida por ela como saber-ser. Não há consenso sobre se é possível a escola formar profissionais competentes uma vez que a competência remete à subjetividade do indivíduo e o estudante é também ator de sua própria formação mas, temos bons indícios para crer que a escola pode exercer um papel que promova a autonomia dos jovens e que os permita experimentar, construir conhecimentos, mobilizar saberes e, quem sabe, desenvolver competências.

\section{Pedagogias alternativas e o foco na aprendizagem}

A despeito da predominância das pedagogias tradicionais no contexto da engenharia, há iniciativas que demonstram ser possível a construção de conhecimentos a partir de outras vias, que não seja unicamente partir da transmissão dos saberes do professor. A propósito, tanto Maggi (2008) quanto Freire (2009) sustentam a tese de que ensinar não é transferir conhecimentos e sim criar as possibilidades para a sua produção ou a sua construção. Maggi (2008) apoia sua argumentação em fatores relacionados à comunicação e à efetividade da escuta, isto é, o fato de que o professor transmitiu alguma mensagem não implica o fato de que ele tenha ensinado alguma coisa, não se sabe se a mensagem foi recebida ou como a mensagem foi recebida ou se foi compreendida pelo mesmo ponto de vista que o professor desejou ter "transmitido", não se sabe também se houve recusa do receptor. Freire (2009) critica o que ele chama de "educação bancária", focada quase que exclusivamente no ensino dos conteúdos como "transferência do saber" para a adaptação, que tolhe a liberdade do educando, que não forma, domestica. Diante do que pensam os autores e da forma como a educação em engenharia de fato acontece, como desenvolver a curiosidade epistemológica uma vez que os espaços escolares favorecem a docilidade-utilidade? Os autores também concordam que o aluno não é um "eu" isolado, ele está inserido em seu contexto social. Para ambos autores, aprender é um agir e o aluno desempenha papel fundamental no seu próprio processo de aprendizagem.

Como afirma Gohn (2001, p 21), "o debate sobre as teorias da aprendizagem voltaram à baila dadas as mudanças provocadas pela globalização e seus efeitos sobre a sociedade e as políticas governamentais". Processos de aprendizagem têm sido discutidos, evidenciados, tido sua importância valorizada. No âmbito da pesquisa, as edições 2015 e 2017 do Congresso Brasileiro de Educação em Engenharia (COBENGE) tiveram temas centrais relacionados às inovações no ensino e na aprendizagem com destaque para a interdisciplinaridade e para iniciativas de algumas instituições no sentido de adotarem metodologias ativas no processo de ensino e aprendizagem nos cursos de engenharia, tais 
iniciativas podem ser encaradas como pedagogias alternativas às tradicionais, majoritariamente presentes no contexto da engenharia.

Pedagogias alternativas são iniciativas que diferem das tradicionais porque, enquanto estas são diretivas e centradas no ensino, as alternativas colocam a centralidade no aprendiz e entendem que a construção dos conhecimentos pode se dar por outras vias que não seja unicamente a transmissão dos saberes do professor. Compreendem que os interesses, motivações e desejos dos alunos são fundamentais para o processo de aprendizagem, favorecem a autonomia e impulsionam a curiosidade epistemológica de forma que o aluno desempenhe um papel ativo no seu próprio processo formativo.

Os anais do COBENGE de 2015 citam como estratégias e metodologias de aprendizagem ativa utilizados nos cursos de engenharia em universidades brasileiras e estrangeiras (e. g. Portugal, Dinamarca, Estados Unidos, Singapura) a aprendizagem baseada em problemas e em projetos, instrução pelos colegas, pense-par-compartilhe, grupos resolvendo exercícios em sala de aula, tomando notas em pares, dentre outras (COBENGE, 2016).

Além das iniciativas pedagógicas alternativas propostas por professores e pesquisadores e instituições, é importante ressaltar que os alunos também são capazes de intervir, de criar alternativas, de resistir, de atuar na sua própria formação. Ao assumirem a posição de quem se insere no sistema escolar e não apenas a de quem se adapta a ele os alunos também modificam e constroem a escola que desejam.

Para evidenciar estes fatos, tomamos como exemplo duas práticas pedagógicas que acontecem ou convivem com os cursos de engenharia do CEFET-MG sendo uma proposta por um professor e outra iniciada por alunos, são elas: as apresentações do trabalho final da disciplina metodologia de projetos da turma do segundo período da engenharia elétrica e uma sondagem inicial acerca de uma equipe de competição existente na instituição.

No caso da disciplina metodologia de projetos, a atividade proposta pelo professor é que os alunos desenvolvam, ao longo da disciplina, em equipes, um projeto de engenharia que eles mesmos escolhem. É importante ressaltar que os alunos de engenharia elétrica do segundo período ainda cursam a formação básica em engenharia e que a única disciplina de caráter técnico que eles tiveram contato foi programação de computadores com exceção para aqueles alunos que obtiveram formação técnica prévia em outros cursos. Ao final do semestre são feitas as apresentações dos projetos desenvolvidos.

A partir das apresentações dos projetos fica evidente que os estudantes possuem um entendimento próprio da engenharia associado à resolução de situações problema. Foram no total sete grupos sendo que um apresentou um projeto relacionado à acessibilidade de deficientes visuais, três apresentaram projetos que visam à eficiência energética, um apresentou um projeto de sonorização ligado a uma motivação pessoal, um 
apresentou um projeto relacionado à necessidade medição de nível e o último apresentou um projeto de automação residencial relacionado a conforto e bem estar. Os estudantes, mesmo sem terem tido as aulas de todas as disciplinas técnicas que precisariam para o desenvolvimento dos projetos conseguiram cumprir as tarefas. Algumas equipes construíram inclusive protótipos. Questionados sobre as dificuldades da execução das atividades e sobre como fizeram para aprender aquilo que ainda não tinham estudado, muitos responderam que lançaram mão da pesquisa e aprenderam o que precisaram. Em alguns grupos havia alunos com conhecimentos prévios pelo fato de terem frequentado anteriormente cursos técnicos e as equipes de competição do CEFET. Nestes casos, os alunos com conhecimentos prévios atuaram como auxiliadores para o restante do grupo.

A equipe Fórmula Cefast é uma equipe de competição fundada em 2005 por iniciativa de alunas do curso de engenharia mecânica do CEFET-MG. A equipe constrói carros tipo fórmula para participar da competição Fórmula SAE Brasil7. A competição é composta por provas estáticas e dinâmicas e por apresentações técnicas das equipes que inclui projeto, custo e marketing. A avaliação é feita por engenheiros especialistas. Na última edição da competição, em 2016, a equipe Fórmula Cefast alcançou o terceiro lugar dentre quarenta equipes de universidades competidoras, o que demonstra que esta iniciativa tem alcançado papel de destaque no cenário nacional.

A sondagem inicial nos mostrou que a equipe Cefast acontece por iniciativa e empenho dos próprios alunos com apoio de um professor. Os carros fórmula são projetados e construídos pelos próprios alunos. Cada área de conhecimento mobilizada pelo projeto do carro é composta por um aluno responsável e sua equipe, também composta pelos alunos de engenharia. Há alunos de administração que trabalham com os pedidos de compras de materiais e inscrições da equipe nas competições dentre outras atividades administrativas. $A$ sondagem inicial mostra que o que parece acontecer na equipe é uma espécie de autogestão, os próprios integrantes da equipe fazem o processo seletivo dos novos integrantes. Mesmo que não haja cobrança formalizada por cumprimento de horários, os alunos se comprometem com o trabalho das equipes e com os resultados deste trabalho de forma que a cobrança por cumprimento de horários não se faz necessária. Há troca de saberes entre os alunos mais e menos experientes em um espírito de colaboração. Alunos em início de curso, que ainda não tiveram contato com as disciplinas técnicas, podem ter oportunidades de aprender e desenvolver na equipe atividades técnicas. Questionado sobre as motivações que levam os alunos a se dedicarem tanto à equipe e, muitas vezes, demonstrarem menor dedicação em sala de aula, um ex-integrante respondeu que "muitos alunos são apaixonados pela equipe", que na equipe os trabalhos são desempenhados por

${ }^{7}$ No Brasil a $1^{\text {a }}$ competição do Fórmula SAE ocorreu no ano de 2004. Atualmente a competição acontece na Austrália, Itália, Inglaterra, Alemanha, Brasil e Estados Unidos, onde são reunidas as melhores equipes de cada país. 
escolha dos alunos, que a equipe é mais "aberta" que a sala de aula, e que o aprendizado é mais livre, que o resultado é visto dia após dia e que o aluno não precisa aprender com a finalidade de fazer uma prova. A partir desta sondagem inicial é possível inferir que a equipe parece auxiliar a troca de saberes entre os estudantes e incentivar sua autonomia, os situando na condição se indivíduos ativos no processo de aprendizagem.

Outro ponto levantado pela sondagem inicial diz respeito aos professores dos cursos de engenharia. Segundo os alunos eles parecem não se interessar pelas atividades de aprendizagem que acontecem nas equipes, eles não possuem um papel nem no sentido de incentivar os alunos a se envolverem nestas atividades e nem de dissuadi-los.

É evidente que tanto a disciplina de metodologia de projetos quanto as atividades da equipe Fórmula Cefast são práticas formadoras não convencionais dentro do contexto da engenharia, alternativas à pedagogia tradicional proposta pela escola. $O$ fato de a atividade de metodologia de projetos ter sido proposta por um professor, isoladamente, denota que o entendimento da educação por parte dos professores pode não ser unânime, que os professores possuem entendimentos diferentes acerca de como a educação deve acontecer. $\mathrm{O}$ fato de as atividades da equipe Fórmula Cefast acontecerem por iniciativa e empenho dos alunos e eles serem capazes de trocar saberes e construir conhecimentos evidencia o fato de que, ainda que a escola possua seu currículo, seus métodos e suas práticas, os alunos também são atores dentro dos seus próprios processos formativos, ou seja, os alunos também constroem a escola. Pedagogias alternativas podem, então, existir independentemente da pedagogia que propõe a escola, podem existir em sala de aula ou mesmo fora dela, podem partir de um professor que tenha um entendimento mais amplo acerca da educação ou mesmo dos próprios alunos, motivados pelas suas vontades, desejos e interesses. Pedagogias alternativas podem coexistir com as tradicionais, complementá-las ou mesmo serem encaradas como estratégias de resistência ao autoritarismo das pedagogias tradicionais e podem demonstrar o tipo de educação que desejam os principais atores do processo educativo que são os alunos.

É importante ressaltar que o que está em questão nesta pesquisa não é a substituição das pedagogias tradicionais pelas alternativas e nem a hierarquização destas sobre aquelas, que a importância da sala de aula e do professor é inegável. O que se propõe é pensar que as pedagogias alternativas podem dar aos jovens uma vivência diferente na universidade, agregar experiências em seus percursos formativos que os permitam desenvolver outras habilidades, saberes e inclusive outra forma de compreender a escola.

\section{Referências}


AMORIM, Mário. L., Qual engenheiro? - Uma análise dos projetos político-pedagógicos dos cursos de engenharia da Universidade Tecnológica Federal do Paraná (UTFPR). Revista de Ensino de Engenharia, Brasília: v. 35, n. 1, p. 23-33, 2016.

BOURDIEU, Pierre. Escritos de educação. 16 ed. Petrópolis: Vozes, 2015.

CAVACO, Cármem. Aprender fora da escola: percursos de formação experiencial. Lisboa: Educa, 2002.

CAVAlCANTE, Alberto. R., AlBUQUERQUE, Antônio. C., JESUS, Cláudio. R. Dilemas da sociedade do trabalho. 2. ed. rev. Belo Horizonte: Argvmentvm, 2008.

COBENGE, Desafios da educação em engenharia: processos de ingresso, perfil do professor, aprendizagem multidisciplinar, inovação e proposições/ Vanderlí Fava de Oliveira, Octavio Mattasoglio Neto e Marcos José Tozzi - organizadores - Brasilia: ABENGE, 2016.

DADOY, Mireille. Competência e competências: os usos sociais da noção de competência à luz de transformações que afetam o modo de gestão da mão-de-obra. In: TOMASI, Antônio de Pádua Nunes (org.) Da qualificação à competência: pensando o século XXI. Campinas: Papirus, 2004.

DAGNINO, Renato. NOVAES, Henrique. T. O papel do engenheiro na sociedade. Revista Tecnologia e Sociedade, Curitiba, v. 4, n. 6, 2008.

DUGUÉ, E. A lógica da competência: o retorno do passado. In: TOMASI, Antônio de Pádua Nunes (org.) Da qualificação à competência: pensando o século XXI. Campinas: Papirus, 2004.

FOUCAULT, Michel. Vigiar e punir: nascimento da prisão. 42. ed. Petrópolis: Vozes, 2014.

FREIRE, Paulo. Pedagogia da autonomia: saberes necessários a prática educativa. 39. ed. São Paulo: Paz e Terra, 2009.

FRIGOTTO, Gaudêncio. A relação da educação profissional e tecnológica com a universalização da educação básica. Revista Educação e Sociedade, Campinas, v. 28, n. 100, out. 2007.

GAMA, Ruy. A tecnologia e o trabalho na história. São Paulo: Nobel/EDUSP, 1986.

GOHN, Maria. G. Aprendizagens em pedagogias alternativas: Movimentos sociais. Desigualdade \& Diversidade: Revista de Ciências Sociais da PUC-Rio, n 12, p. 12-27, jan./dez. 2013.

LIMA, Licínio. C. Educação ao longo da vida: entre a mão direita e a mão esquerda de Miró. São Paulo: Cortez, 2007.

LODER, Liane. L. O professor-engenheiro: formar como e para que?. In: OLIVEIRA, Vanderli F. Educação, mercado e desenvolvimento: mais e melhores engenheiros. São Paulo: Abenge, 2008.

MAGGI, Bruno. Pode-se transmitir saberes e conhecimentos?. Revista Educação e Tecnologia, Belo Horizonte, v. 13, n. 3, p. 53-64, set/dez. 2008. 
ORTEGA Y GASSET, José. Meditação da técnica. Rio de Janeiro: Livro Ibero-Americano, 1963.

RIBEIRO, Luis. Roberto. de Camargo. A aprendizagem baseada em problemas (PBL): uma implementação na educação em engenharia na voz dos atores.2005. 209 f. Tese (Doutorado em Educação) - Centro de Educação e Ciências Humanas, Universidade Federal de São Carlos. São Carlos, 2005.

SALOMON, Jean-Jacques., What is technology? The issue of its origins and definitions. History and Tecnology, v. 1, n. 2, p. 113-156, 1984. Disponível em: <http://dx.doi.org/10.1080/07341518408581618>. Acesso em: 20 dez. 2017.

SILVA, Jarbas. C. O processo de aprendizagem, formação e desenvolvimento de saberes do engenheiro por meio do projeto do veículo CEFAST BAJA no CFET-MG. Dissertação (Mestrado em Educação Tecnológica) - Centro Federal de Educação Tecnológica de Minas Gerais - CEFET-MG. Belo Horizonte/ MG, 2017.

SILVEIRA, Marcos. A.; et al. Pesquisa em Educação em Engenharia. In: CONGRESSO BRASILEIRO DE EDUCAÇÃO EM ENGENHARIA, 35., 2007, Curitiba. Anais... Brasília: ABENGE, 2007.

SILVEIRA, Marcos. A.; CARMO, Luís. C. S.; SILVA, Evandro. M. Considerações sobre o mercado de trabalho em engenharia. In: OLIVEIRA, Vanderli F. Educação, mercado e desenvolvimento: mais e melhores engenheiros. São Paulo: Abenge, 2008.

TOMASI, Antônio. P. N. Qualificação ou competência?. Revista Educação e Tecnologia, v. 7 n. 1 jan./jun. 2002.

TOMASI, Antônio. P. N. Quando uma pedagogia alternativa de formação de adultos ocupa a escola. HIG, Belo Horizonte, v. 1, n. 1, p. 83-113, nov. 2017. 